\title{
Human Resource Development Climate (HRDC) in the Banking Sector: General and Gender Perceptions
}

\author{
Benjamin O. Akinyemi ${ }^{1}$ \\ ${ }^{1}$ Department of Industrial Management Systems and Operations, Botswana International University of Science \\ and Technology (BIUST), Palapye, Botswana \\ Correspondence: Benjamin Akinyemi, Department of Industrial Management Systems and Operations, College of \\ Management and Entrepreneurship, Botswana International University of Science and Technology, Private Bag \\ 16, Palapye, Botswana. Tel: 267-7663-8791. E-mail: akinyemi.ben@gmail.com
}

Received: March 31, 2014

doi:10.5539/ijbm.v9n10p77

\author{
Accepted: August 9, 2014 \\ Online Published: September 25, 2014
}

URL: http://dx.doi.org/10.5539/ijbm.v9n10p77

\begin{abstract}
This study examines the state of Human Resource Development Climate (HRDC) in Nigerian commercial banks as perceived by employees in general. The perceptional differences on the level of HRDC by gender categories are also examined. Using Abraham and Rao's HRDC 38-item questionnaire, data from 310 respondents, with 303 valid responses, were entered into excel sheet and analyzed to determine frequencies, mean scores, standard deviation and percentages for four variables: HRDC, General Climate, HRD Mechanism, and the openness, confrontation, trust, autonomy, pro-activity, authenticity and collaboration (OCTAPAC) Culture. Result of data analysis indicates that generally, employees perceive the overall HRDC and its three dimensions of general climate, HRD mechanism and OCTAPAC culture to be at an average or moderate level. The perceptions of both male and female subjects also indicate an average HRDC level although female participants report slightly higher scores than the male subjects but these scores are still at an average level on all the dimensions of HRDC measured. The implications of this result for organizations in general and the banking industry in particular are discussed.
\end{abstract}

Keywords: human resource development climate (HRDC), HRD mechanism, general climate, culture, gender

\section{Introduction}

In the $21^{\text {st }}$ Century's highly competitive business environment human resource holds the key to sustainable competitive advantage (Akinyemi, 2009). It is not enough to develop HRD strategy. The litmus test of successful HRD strategy implementation is seen in the perception of employees whose workplace attitude and behavior are influenced and predicted by it. Their perception of organizations' human resource development environment has been found to influence citizenship behavior and voluntary turnover intention (Akinyemi, 2012). This is quite significant and pivotal as far as organizational effectiveness, success and sustainability are concerned.

The focus of this paper is an assessment of the prevailing HRDC in Nigeria's banking industry. This financial sub-sector has witnessed series of reforms, change and transformation in recent times, in the form of restructuring, mergers, acquisitions, liquidations, etc. Surviving banks have had to embark on series of interventions to ensure stability, growth and profitability. What is the impact HRD activities and environment on employees? How do the employees perceive their banks' HRD environment? This study examines the perception of employees in general about the prevailing organizational HRDC in the Banks in order to identify areas where interventions are required. Furthermore, the study also investigates the perceptional differences by gender categories. The paper is divided into the following sections: Introduction, Nigerian banking sector, organizational climate and culture, HRD climate, dimensions of HRD climate, Human Resource Development, methodology, results and discussion, implications and conclusion.

\section{The Nigerian Banking Sector}

The recent rebasing and re-benchmarking of Nigeria's GDP base did not only made the country the largest economy in Africa but also changed the structure of its economy. The services sector is the biggest contributor to this robust economic performance (Table 1). For instance, the share of this sector, comprising financial, construction, entertainment, IT, nearly doubles from $26 \%$ to $51 \%$ (Masetti, 2014). The Nigerian banking industry 
is the fastest growing sub-sector in the financial services sector and has not only contributed to the current improved GDP but has also made significant contributions to the nation's economic growth (Sanusi, 2011; Iyoboyi, 2013).

Table 1. Re-basing and change in Nigeria's GDP structure

\begin{tabular}{lcc}
\hline \multirow{2}{*}{ Industry } & \multicolumn{2}{c}{ Rebasing Share in Total GDP, \% } \\
\cline { 2 - 3 } & Pre-rebasing (\%) & Post-rebasing (\%) \\
\hline Agriculture & 33 & 22 \\
Manufacturing & 2 & 7 \\
Hydrocarbon & 37 & 16 \\
Services & 26 & 51 \\
Other Industry & 2 & 4 \\
\hline
\end{tabular}

Source: Deutsche Bank Research (2014).

The banking sector is one the most dynamic and matured sectors of the Nigerian economy (Ogba, 2008) and has witnessed significant changes in structure, culture and operations (Soludo, 2004). Reforms and changes in the sector, since 1986, ranged from deregulations to liberalization and recapitalization often leading to mergers, acquisitions, restructuring, downsizing or liquidations. This situation put enormous pressure on commercial banks to compete for, develop and retain the best available skilled professionals without which success and sustainability are unattainable. It is in this light that the present study seeks to investigate the state of internal development environment within the sector. Employee development holds the key to unlocking and unleashing individual potentials for the benefit of the organization especially when there is intense competition for market share, highly talented and skilled employees. Examining the state of HRDC as perceived by employees in an important sector such as the Nigerian banking industry is expected to reveal the level of importance placed on creating and developing a congenial or conducive environment for employees.

\section{Organizational Culture and Climate}

Organizational climate and culture are two distinct terms that have sometimes been used interchangeably. To differentiate these concepts, Agarwal and Maloy (1999) state that: "Climate refers to the members' shared perception of how the organization operates whereas culture refers to the administration's and the members' assumption about how the organization does and ought to operate" (p. 2). Another definition of climate as different from culture is: "a set of conditions that exist and have an impact on individual's behavior" (Denison (1990, p. 24). Organizational culture, however, is viewed as the deep structure of organizations, which is rooted in the values, beliefs and assumptions held by organizational members (Denison, 1996). As defined by French et al. (1985) climate is "the relatively persistent set of perceptions held by organization members concerning the characteristics and quality of organizational culture. It describes members' organizational experience and the shared meanings they attach to their perceptions of organizational environment (Schneider, Smith \& Goldstein, 2000). While culture is seen as a description of the social context of the work environment, climate describes its psychological impact. Climate, therefore, could be described as "a manifestation of organizational culture, whereas culture subsumes climate" (Agarwal \& Maloy, 1999, p. 2) and it is significant to making organizations get the best out of themselves (Rao, 1999).

Ekvall (1987) suggested that there are two ontological interpretations of the organizational climate concept: realistic and objectivistic; and subjectivistic and phenomenological. The objectivistic view sees climate as an attribute of the organization while, according to the subjectivistic approach, organizational climate is the organizational members' common perception of the organizational situation. It is regarded as "a product of personal values and remains a property of individuals irrespective of the empirical level of anaylsis" (James, James, \& Ashe, 1990).

Apart from general organizational climate and culture there are sub-sets of organizational climate and culture. Examples of organizational climate sub-sets are: organizational communication climate, ethical climate, social climate, organizational transfer climate, service climate and Human Resource Development climate, among others. It is important to note that HRD culture is embedded in organizational culture and the development of HRD culture is essential for organizational success (Singh and Sen, 1992). Underscoring the importance of climate, Bowen and Ostroff suggested that organizational climate is a crucial link between human resources management and performance. Along this line of thought, they defined organizational climate as "a shared 
perception of what the organization is like in terms of practices, policies, and procedures what is important and what is rewarded" (2004, p. 204). The HRDC sub-set of organizational climate is, therefore, important and a major determinant of employee engagement and organizational development.

\section{Human Resource Development Climate}

HRDC, as a sub-set of organizational climate, is the perception of employees about employee development environment or the psychological impact of an organization's employee development policies, practices and procedures. An organization's HRDC relates to the visible characteristics of HRD corporate culture (Wexley \& Latham, 1991). Research findings show that employee perception of the work environment drives work attitudes and performance (Parker, et al., 2003). The perception of employees is very important because of its attitudinal and behavioral consequences (Schneider et al., 2000) with impact on organizational success.

The significance of HRDC cannot be over-emphasized. A study by Abraham (1989) indicates that a good HRDC rather than HRD practices by themselves are actually responsible for organizational performance. Other things being equal, an organization with a better HRDC, competent and committed employees could outperform an organization that scores low on these counts. Some studies have actually linked climate and performance (Denison, 1990; West et al., 1998; Burke \& Litwin, 1992; Kangis \& Williams, 2000) claim that when employees perceive greater involvement in decision-making, information sharing and management support as favorable, it results in greater corporate effectiveness. Pattnayak (1998) posits that HRDC's impact on individual performance is visible in three ways i) by defining the stimuli that confronts the individual, ii) by placing constraints on the individual "s freedom of choice and iii) by providing source of reward and punishment. Athreya (1998) maintains that HRD system that supports a positive HRDC leads to a more effective existing systems and enables organizations to be more receptive to new HR practices (Athreya, 1998). In a study by Mohanty, et al., (2012) HRDC was found to have a positive influence on job performance of the employees of private insurance companies in Odisha. It should, however, be noted that an appropriate HRDC can only be created through good HRD practices and processes. HR practices contribute to organizational effectiveness through HRDC and HRD outcomes such as: competency, motivation and commitment development (Rao, 1986).

\section{Dimensions of HRDC}

Human Resource Development Climate is the perception of the employee about the HRD systems, mechanisms, processes and outcomes as an organization deals with its members, groups and issues. The study follows the typology of HRDC as developed by Rao and Abraham (1986). They identified three HRDC elements, which are: General Climate, HRD Mechanism and OCTAPAC Culture.

\subsection{General Climate}

General climate provide the views on the top management and line managers' support for HRD. It centres on the attitudes and the behaviors of superiors/supervisors towards employee development. It deals with the practical concerns that top management and other managers/supervisors have regarding the growth and development of subordinates-whether these are genuine or not. The general climate deals with what the bosses at the top are doing rather than what they are saying, that is, the level of top management's sincerity and determination in taking appropriate actions towards workforce development. It focuses on an actual support for development and not just a pledged or verbal support-what is being done and not what is being promised. It assesses the belief of top management in human resource development and examines the existing superior-subordinate relationship as perceived by individual organizational members.

\subsection{HRD Mechanism}

HRD mechanisms dimension deals with HRD sub-systems such as, performance management, potential appraisal, training and development, career planning and development, reward management, quality of work life, self renewal mechanisms, etc. This element examines the implementation of HRD sub-systems such as training, employee appraisal and feedback, career planning, rewards and employee welfare. While it is important to develop HRD strategies attention should be given to how the strategies are implemented and not their sophistication parse. HRD Mechanisms focuses on the practicalities of the HRD sub-systems and the main issue is how each employee perceives the implementation based on his/her experience within the organization. Issues of organizational justice, fairness, trust, respect, etc. are also covered by this element of HRDC.

\subsection{OCTAPAC Culture}

OCTAPAC culture refers to the degree of openness, confrontation, trust, autonomy, pro-activity, authenticity and collaboration that exist in the organization. The OCTAPAC element examines the psychological state of the organization's development environment-whether it is conducive to creativity and innovation or not. A 
repression and punishment oriented environment only produces inhibitions and fear which do not encourage critical thinking, creativity and innovation. Employee development can only flourish within a congenial environment of freedom of expression and experimentation. If the OCTAPAC culture is absent employee growth and development are hindered. This dimension deals with "an environment of trust, opportunities to take decision and be innovative, a proactive attitude towards development by the employees and line mangers, a authentic approach towards developmental issues, and positive attitude for settling matters of dispute and grievances forthrightly with positive interaction" (Mohanty et al., 2012).

\section{Human Resource Development (HRD)}

HRD has grown through many stages, beginning thousands of years ago when artisans handed down knowledge and skills of the earliest crafts to younger generations, often through some kind of apprenticeship, which was as early as $2100 \mathrm{BC}$. It has become an evolving concept for building workforce performance to meet the needs of an organization. The first formal concept of human resources development appeared in a General Assembly resolution in December 1989. Resolution 44/213 not only defined human resources development but also identified its essential elements, stating that "human resources development is a broad concept encompassing many components and requiring integrated and concerted strategies, policies, plans and programs to ensure the development of the full potential of human beings...so that they may individually and collectively be capable of improving their standard of living. It is a specific means to achieve specific economic goals." Further elaboration of human resources development is found in a General Assembly draft resolution (A/C.2/48/L.56). The foundation of HRD is built around two key principles:

(a) People are central to all development activities; and

(b) Human resources development is an essential means of achieving sustainable development goals.

HRD has been defined in variety of ways to stress its strategic role in Organizational Development. It "is a process for developing and unleashing human expertise through organization development and personnel training and development for the purpose of improving performance" (Swanson and Holton III, 2001). It is also defined by McLean and McLean (2001) as "any process or activity to develop adults' work-based knowledge, expertise, productivity, and satisfaction, whether for personal or group/team gain, or for the benefit of an organization, community, nation, or ultimately, the whole of humanity." McLean and McLean (2001, p. 10) offered an expanded definition to underscore its evolutionary nature. They described it as "any process or activity that, either initially or over the long term, has the potential to develop... work-based knowledge, expertise, productivity and satisfaction, whether for personal or group/team gain, or for the benefit of an organization, community, nation, or ultimately, the whole of humanity." Another definition by Chalofsky (1992) states that it is "the study and practice of increasing the learning capacity of individuals, groups, collectives, and organizations through the development and application of learning-based interventions for the purpose of optimizing human and organizational growth and effectiveness."

In the latest definition (Desimone, et al., 2002) HRD was defined as "a set of systematic and planned activities designed by an organization to provide its members with the opportunities to learn necessary skills to meet current and future job demands". It is recognized as the framework for helping employees develop their personal and organizational skills, knowledge, and abilities (Tvetipedia, 2014) and includes such opportunities as employee training, employee career development, performance management and development, coaching, succession planning, key employee identification, tuition assistance, and organization development. It can best be described as a comprehensive learning system designed to enhance individual performance for the purpose of improving organizational efficiency. It includes three types of learning activities: on the job, off the job, and through the job in formal and informal manner. As an organizational function, Hatcher (1999) posits that HRD plays a significant role in "enhancing the long-term sustainability of organizations and has the potential to help cultivate organizations and people that positively influence individuals, communities, society, and the environment."

A 1994 UN Expert Group Meeting on Human Resources Development reported that: "Human resources development by any definition is an extremely complex problem to address. It is linked to other concepts, including: (1) workforce planning, (2) remedial programs for disadvantaged groups, (3) personnel administration, training, and organizational development, (4) general education and training, and (5) skills and knowledge development."

Human Resource Development operates at macro and meso levels. At the macro level it involves national table policy and planning of HR needs in numbers and skills or competency development to satisfy the needs of existing industries and those the nation is trying to develop. At the meso level, it includes organization's efforts to improve and "understand the interactions, processes, and systems...to support and improve individual, process, 
and organizational learning and performance (Sleezer \& Sleezer, 1997, p. 185). At the micro level, however, HRD is concerned with the impact of macro and meso level interventions on the worker's competency, skill and knowledge development. At this micro level, it also examines the systems that act to foster or hinder individual development, career growth and organizational commitment. HRD system that supports a positive HRDC makes existing systems more effective and makes organizations more receptive to new HR practices (Agarwala, 2002). The focus of HRD is on developing the most superior workforce so that the organization and individual employees can accomplish their work goals in service to customers.

\section{Significance of Study}

This study is significant to organizations in general and the Nigerian banking sector in particular. We are in the era of change which is being driven by intense competition, globalization, technology, talent and demographic shift. For organizations to gain and sustain the much desired competitive edge there is the need for commitment to excellence, creativity and innovation. However, the capability for innovation and creativity reside only in human capital and not in tangible organizational assets (Drucker, 1999; Kessels, 2009). Unless HRD is given top priority and people have access to opportunities to upgrade their skills, develop their abilities and improve their knowledge organizations would find it difficult to gain and sustain the competitive edge. The perceptions of employees about the prevailing HRDC is an indication of organization support for employee development, implementation of development related strategies, organizational readiness for change and the leaning of organizations towards the culture of innovation. An understanding of the prevailing HRDC serves as a compass for organizations and gives direction in developing and implementing appropriate strategy for employee development.

\section{Methodology}

\subsection{Study Objectives}

The study sets out to examine the state of HRDC in the Nigerian banking industry with regards to the following:

a. The state of overall HRDC in the banking sector;

b. The state of HRD mechanism in the banking sector;

c. The state of general HRDC in the banking sector;

d. The state of OCTAPAC culture in the banking sector;

e. Employees' perception of HRDC in the banking sector by gender.

\subsection{Instrument}

The survey questionnaire used in this study is the 38-item HRDC instrument developed by Rao and Abraham (1986). Items in the questionnaire categorized HRDC into three dimensions: general climate, HRD mechanism and OCTAPAC culture with 14, 15 and 10 items respectively. Possible responses were arrayed on a five-point Likert scale comprising "strongly disagree" (5), "disagree" (4), "neutral" (3), "agree" (2), and "strongly agree" (1). Test of internal consistency (Cronbach's alpha) was conducted to assess the reliability of the HRDC questionnaire used in this study. The result (0.96) indicates that the HRDC questionnaire showed an adequate level of internal consistency reliability.

\subsection{Participants}

Participants comprise full-time managerial and non-managerial employees of eight commercial banks located in the South-Western part of Nigeria. Analysis is based on 303 usable questionnaires out of 310 which were returned by respondents.

\subsection{Data Analysis}

To analyze the data, simple interpretative techniques such as mean scores, percentages and standard deviation were calculated using Excel. Test of internal consistency (Cronbach's alpha) was conducted to assess the reliability of the HRDC questionnaire used in this study. The result (0.96) indicates that the HRDC questionnaire showed an adequate level of internal consistency reliability.

\section{Result and Discussion}

Table 2 shows the result of data analysis for overall HRDC and its three dimensions. The result indicates an average or moderate levels of overall HRDC with a mean score of $2.55(51 \%)$; general climate with a mean score of $2.52(50 \%)$; HRD mechanism with a mean score of $2.53(51 \%)$ and OCTAPAC culture with a mean score of $2.60(52 \%)$. 
Table 2. Analysis of overall HRD climate and its dimensions

\begin{tabular}{lccc}
\hline Dimensions & Mean & Percentage & $\begin{array}{c}\text { Standard } \\
\text { Deviation }\end{array}$ \\
\hline Overall HRD Climate & 2.55 & 51 & 1.08 \\
General Climate & 2.52 & 50 & 1.06 \\
HRD Mechanism & 2.53 & 51 & 1.11 \\
OCTAPAC Culture & 2.60 & 52 & 1.60 \\
\hline
\end{tabular}

In Table 3 the number of respondents according to gender categories was indicated. Male respondents are 165 $(56.27 \%)$ and female respondents constitute $126(43.3 \%)$ of the total (291). Male respondents are more in number than their female counterparts.

Table 3. Distribution of respondents by gender categories

\begin{tabular}{lcc}
\hline Gender & Frequency & Percentage \\
\hline Male & 165 & 56.7 \\
Female & 126 & 43.3 \\
Total & 291 & 100 \\
\hline
\end{tabular}

In Table 4 perceptional differences based on respondents' gender were examined. Result indicates that both male and female respondents perceive the prevailing HRDC to be at average level. However, female participants recorded slightly higher scores than their male counterparts on all the dimensions of HRDC measured but this slightly higher score is negligible and does not change the average level HRDC scores.

Table 4. Perceptional differences on HRDC by gender

\begin{tabular}{lcccccc}
\hline HRDC Dimensions & Male & & \multicolumn{3}{c}{ Female } \\
\hline & Mean & Percentage & SD & Mean & Percentage & SD \\
\hline Overall HRD Climate & 2.50 & 50.24 & 1.03 & 2.55 & 50.99 & 1.07 \\
General Climate & 2.48 & 49.72 & 1.04 & 2.52 & 50.46 & 1.07 \\
HRD Mechanism & 2.51 & 50.09 & 1.10 & 2.52 & 50.29 & 1.09 \\
OCTAPAC Culture & 2.52 & 50.90 & 1.05 & 2.61 & 52.23 & 1.05 \\
\hline
\end{tabular}

This result agrees with the findings of some previous researchers such as Rao and Abraham (1986) and Rao (1999, 2001). Saxena and Tiwari (2009) reported an average or moderate HRD in 41 public organizations and public sector banks respectively. Riyaz (2000) who studied HRDC in commercial banks found the overall OCTAPAC values at a moderate level. Another study by Pillai (2008) reported a moderate level of HRDC in banks. Some other studies have reported a favorable HRDC. Mittal and Verma (2013) examined employees' perceptions of HRDC in the SBI Bank in Bhopal. The employees have a favorable attitude towards HRD Policies and practices of the organizations. Srimannarayana (2007) found that a good HRDC existed in a Dubai bank and Akinyemi (2012) reported a higher level of HRDC a Rwanda based telecommunication and an insurance company in a comparative study.

\section{Practical Implications of Results}

For HRD professionals, the implications of the outcome of this research in the service industry that thrives on innovative services and cutting-edge technology are obvious. It is pertinent to note that most studies on HRDC assessment in the banking sector have reported an average or moderate level of overall HRDC and its three dimensions. The current study is not an exemption. Yet, human resource remains the most reliable source of sustainable competitive advantage as "physical resources, technology and financial acumen now fall short of the enabling powers they once possessed as critical success factors for sustainable competitive advantage because of transition into the new economy where human knowledge, skill, and capabilities are key success factors" (Akinyemi, 2009). 
In view of the utmost importance of human resource to the financial services sector, especially the banking sector, HRD specialists need to be more proactive, innovative and flexible in managing and developing organizational workforce. Three things are indispensable: investment in human capital, creating an enabling (congenial or supportive) environment and developing and utilising innovative human resource development practices (Akinyemi, 2012). Investing in people is not an option but an obligation from the point of entry of an employee to the point of departure from the organization. Investing in talent is beneficial to organizations in three major ways: a) enabling those organizations that are resource constrained or have had to reduce headcount in the face of increasing demand to do-more-with less, b) preventing the talent drain when economic conditions improve, and c) investing in leadership to avoid the high costs of staff turnover as the number one reason that employees give for leaving an organization is dissatisfaction with their immediate superior (Ogden, 2011 in Nel et.al, 2011). Creating an enabling environment that is void of inhibitions encourages creativity and innovation and makes it possible for employees to easily unlock and unleash their potentials for the benefit of the organization. The need to utilize innovative HRD practices stem from the reality of the rapidly changing external environment and the need to keep pace with this constant change. The common practice, in the banking sector, of using financial incentive to ensure attract and retain talent is bound to fail when employees perceive a lack of organizational commitment to employees' career growth and development. Financial incentive must accompany employee development to produce the desired retention result.

This result of this study also has implications for the banking sector. The significance of HRDC in the banking industry cannot be underestimated especially because the industry characterised by extensive division of labour, high interdependence of services, high expectations from internal and external customers, and high dependence on information technology (Sekhar, undated). This sector has the capacity to employ a large number of widely divergent groups of highly qualified and talented professionals and it is imperative to ensure strategic workforce development and congenial work environment in order to turn strategic goals to reality.

Currently, the study of HRDC is yet to attract much attention among researchers in developing countries (except in India). The present study is a pioneering effort into an often overlooked but important area of investigation, especially, in Nigeria. Associated with this area of study is an investigation into readiness for change, learning, creativity and innovation climate. Studies are encouraged in these areas since they are closely related to HRDC. Specifically, further studies on HRDC across sectors need to be conducted to underscore the relevance of HRDC as a major source of sustainable competitive advantage for organizations.

\section{Conclusion}

This study is an assessment of the state of HRDC in selected Nigerian commercial banks as perceived by employees. Results show that HRDC is at an average level as perceived by respondents generally and also by gender categories (of male and female). This is the case in the three dimensions of HRDC, i.e. the general climate, human resource development mechanism and OCTAPAC culture. It is a clear indication that employees' confidence in supervisors and top level management, their perception about existing HRD sub-systems such as training, employee appraisal and feedback, career planning, rewards and employee welfare and the degree of openness, confrontation, trust, autonomy, pro-activity, authenticity and collaboration that exist in the organization are at an average level. This situation portends a serious danger for a financial services sub-sector that relies heavily on employees for cutting edge innovation, new product development and customer satisfaction for success in a rapidly changing, highly competitive and globalized business environment. Success and sustainability are guaranteed when organizations consciously promote corporate entrepreneurship and encourage the generation and development of innovative ideas.

The banking sector needs to come to the realization that employees have other important needs that monetary incentives cannot satisfy and this underscores the significance of human resource practices that lead to employee commitment, satisfaction, and retention. In view of this, organizations should give necessary support for employee development by providing a congenial environment and adopt human resource policies and practices that encourage learning, creativity and innovation. Such improved HRDC would have positive impact on employees' behavior and attitude, i.e., employee commitment, job satisfaction and citizenship behavior, turnover intentions and actual turnover. In the volatile and unpredictable business environment of the $21^{\text {st }}$ century characterised by technological revolution, knowledge economy and globalization positional or static organizations are bound to fail. Only those organizations that score high on the elements of HRD climate would be able to gain and sustain the competitive edge in the present innovation economy. 


\section{References}

Abraham, E. (1989). A Study of Human Resource Development Practices in Indian Organizations. Unpublished Doctoral Dissertation, Gujarat University, Ahmedabad.

Akinyemi, B. O. (2009). Human capital management for sustainable competitive advantage in the new economy. In Torres-Coronas, T. \& Arias-Olivia, M. (Eds.), Encyclopedia of Human Resources Information Systems: Challenges in E-HRM (pp. 441-450). Idea Group Publishing, 1(A-H).

Akinyemi, B. O. (2011). An assessment of human resource development climate in Rwanda private sector organizations. International Bulletin of Business Administration, 12, 66-78.

Akinyemi, B. O. (2012a). Determinants of employee outcomes: Evidence from research and practice. Being a presentation at the workshop on Developing the Capability of Rwanda Capacity Builders organized by Kenya Institute of Bankers and the School of Finance and Banking, Kigali, Rwanda.

Akinyemi, B. O. (2012b). Human resource development climate as a predictor of citizenship behavior and voluntary turnover intentions in the banking sector. International Business Research, 5(1), 110-119. http://dx.doi.org/10.5539/ibr.v5n1p110

Asmawi, A., \& Mohan, A. V. (2010). Understanding patterns of organizational culture: A study in Malaysian R\&D institutions, Management of Innovation and Technology (ICMIT). 2010 IEEE International Conference, 324-329. http://dx.doi.org/ 10.1109/ICMIT.2010.5492710

Athreya, M. B. (1988). Integrated HRD System- Intervention Strategies. In T. V. Rao, K. K. Verma, Anil K. Khandelwal, \& E. Abraham, S. J. (Eds.), Alternative Approaches and Strategies of HRD (p. 378). Jaipur: Rawat Publications.

Bowen, D. E., \& Orstroff, C. (2004). Understanding HRM-firm performance linkages: The role of the strength of the HRM system. Academy of Management Review, 29, 203-221. http://dx.doi.org/10.5465/AMR.2004.12736076

Burke \& Litwin, (1992). A Causal Model of Organizational Performance and Change. Journal of Management, 8(3), 523-545. http://dx.doi.org/ 10.1177/014920639201800306

Chalofsky, N. (1992). A unifying definition for the human resource development profession. Human Resource Development Quarterly, 3(2), 175-182. http://dx.doi.org/10.1002/hrdq.3920030208

Contreras-McGavin, M. (2004). Changing colleges and universities through individual empowerment: exploring the intersection between institutional actors and their organizations. (Master thesis) ProQuest Dissertations $\&$ Theses database (UMI No. 1424240).

Denison. (1990). Corporate Culture and Organizational Effectiveness (pp. 30-55). John Wiley Sons, New York, NY.

Desimone, R. L., Werner, J. M., \& Harris, D. M. (2002). Human Resource Development (3rd ed.). Orlando, Harcourt College Publishers.

Drucker, P. (1999). Management Challenges for the 21st Century. New York: Harper Business.

Ekvall, G. (1987). The climate metaphor in organizational theory. In B. M. Bass \& P. J. D. Drenth (Eds.), Advances in organizational psychology. Beverly Hills, CA: Sage.

Hatcher T. (1999). Reorienting the theoretical foundations of human resource development: building a sustainable profession and society. In Kuchinke, K. P. (Eds.), Proceedings of the 1999 AHRD Conference. Arlington, VA.

Iyoboyi, M. (2013). Bank and Non-Bank Financial Deepening and Economic Growth: The Nigerian Experience (1981-2010). Economic Notes, 42(3), 247-272. http://dx.doi.org/10.1111/j.1468-0300.2013.12008.x

James, L. R., James, L. A., \& Ashe, D. K. (1990). The meaning of organisations: The role of cognition and values. In B. Sneider, (Ed.), organisational climate and culture. San Fransisco: Jossey-Bass.

Kangis, P., Gordon, D., \& Williams, S. (2000). Organizational Climate and Corporate Performance: An Empirical Investigation. Management Decision, 38(8), 531-540. http://dx.doi.org/10.1108/EUM0000000005371

Kessels, W. M. J. (2009). Designing favourable learning environments in an emerging knowledge economy. Being a pre-conference workshop presentation at the Kigali Institute of Management, Kigali, Rwanda. 
Masetti, O. (2014). Nigeria: The No. 1 African economy. Research Briefing Emerging Markets. Deutsche Bank Research.

McLean, G. N., \& McLean, L. D. (2001). If we can't define HRD in one country, how can we define it in an international context? Human Resource Development International, 4(3), 313-326. http://dx.doi.org/10.1080/13678860110059339

Mital, S., \& Verma, B. L. (2013). HRD Climate in SBI Bank. Pacific Business Review International, 5(11), $7-22$.

Mohanty, B., Aparija, S., \& Amasahu, G. (2012). An empirical study on HRD climate and its impact on job performance in private insurance companies in Odisha. International Journal of Multidisciplinary Research, 2(5), 15-28.

Nel, P., Du Plessis, A., \& San Diego, J. (2011). Managerial implications for managers and HR practitioners: Some longitudinal research findings in New Zealand. Asia Pacific Journal of Business and Management, 2(2), 60-73.

Pareek, U. (1988). Demystifying HRD. Prashasnika, 15(1-4), 229-236.

Parker, C. P., Baltes, B. B., Young, S. A., Huff, J. W., Altmann, R. A., Lacost, H. A., \& Roberts, J. E. (2003). Relationship between psychological climate perceptions and work outcomes: A meta-analytical review. Journal of Organizational Behavior, 2, 389-416. http://dx.doi.org/10.1002/job.198

Pattanayak. (1998). Corporate HRD. Excel Books, New Delhi.

Pillai, P. R. (2008). Influence of HRD Climate on the learning orientation of bank employees. Indian Journal of Industrial Relations, 43(3), 406-418.

Rao, T. V. (1999). HRD Audit: Evaluating the Human Resource Function for Business Improvement. Response Books: A Division of Sage Publications, New Delhi.

Rao, T. V., \& Abraham, E. (1986). Human Resource Development Climate in Indian Organization. In Rao, T. V. \& Pereira, D. F. (Eds.), Recent Experiences in Human Resource Development. Oxford \&IBH, New Delhi.

Reichers, A. E., \& Schneider, B. (1990). Climate and culture: An evolution of constructs. In B. Schneider (Ed.), Organizational climate and culture. San Francisco, CA: Jossey-Bass.

Riyaz, R. (2002). HRD Climate in Commercial banks: An Empirical study. The Business Review, 9(1).

Sayeed, O. B. (1999). Factor structure of HRD climate survey. Mumbai: NITIE (Mimeograph NITIE Mumbai).

Schneider, B., Smith, D. B., \& Goldstein, H. W. (2000). Attraction-selection-attrition: Toward a personenvironment psychology of organizations. In W. B. Walsh, K. H. Craik, \& R. H. Price (Eds.), Personenvironment psychology: New directions and perspectives (2nd ed., pp. 61-85). Mahwah, NJ: Lawrence Erlbaum Associates, Inc.

Sekhar, S. F. C. (Undated). Towards a model of human resource development in banks. Retrieved from http://www.mainstayin.com/HRD\%20in\%20Banks.pdf

Singh, A. K., \& Sen, A. K. (1992). HRD Culture - A Model. MDI Management Journal, 5(1), 113-122.

Sleezer, C. M., \& Sleezer, J. H. (1997). Finding and using HRD research. In R. A. Swanson \& E. F. Holton III (Eds.), Human Research Development Research Handbook. San Francisco, CA: Berrett-Koehler.

Soludo, C. C. (2004). Consolidating the Nigerian banking industry to meet the development challenges of the 21st Century. Address delivered to the special meeting of the bankers committee, 6 July 2004, CBN Headquarter, Abuja. Retrieved from http://www.cenbank.org/OUT/SPEECHES/2004/Govadd-6Jul.pdf

Swanson, R. A., \& Holton, III. E. F. (2001). Foundations of Human Resource Development. Berrett-Koehler Publishers, San Francisco.

Tvetipidia. (2014). Human Resource Development. Retrieved from http://www.unevoc.unesco.org/tvetipedia.0.html?\&tx_drwiki_pi1[keyword]=human\%20resource\%20develo pment

United Nations General Assembly. (1993). Human resources development. Draft resolution. Forty-eighth session, Second Committee. Agenda item 104. (A/C.2/48/L.56).

United Nations. (1994). Report of the United Nations Expert Group Meeting on Human Resources Development (pp. 22-23). In the Public sector held at United Nations Headquarters, New York. 
West, M. A., Smith, H., Feng, W. L., \& Lawthom, R. (1998). Research Excellence and Departmental Climate in British Universities. Journal of Occupational and Organizational Psychology, 71, $261-281$. http://dx.doi.org/ 10.1111/j.2044-8325.1998.tb00676.x. 1998

Wexley, K. N., \& Latham, G. P. (1991). Developing and Training Human Resources in Organization (2nd ed.). New York: Harper Collins Publishers.

\section{Copyrights}

Copyright for this article is retained by the author(s), with first publication rights granted to the journal.

This is an open-access article distributed under the terms and conditions of the Creative Commons Attribution license (http://creativecommons.org/licenses/by/3.0/). 